\title{
HETEROGENEIDADE AMBIENTAL E VARIAÇÃO FLORÍSTICO-ESTRUTURAL EM UM FRAGMENTO DE FLORESTA COM ARAUCÁRIA NA COXILHA RICA - SC
}

\author{
ENVIRONMENTAL HETEROGENETY AND FLORISTIC-STRUCTURAL VARIATION IN A \\ ARAUCARIA FOREST FRAGMENT IN COXILHA RICA, SANTA CATARINA STATE
}

\author{
Roni Djeison Ansolin ${ }^{1}$ Ana Carolina da Silva ${ }^{2}$ Pedro Higuchi $^{3}$ Larissa Cardoso Küster ${ }^{4}$ \\ Tiago de Souza Ferreira ${ }^{5}$ Fernando Buzzi Júnior ${ }^{6}$ Marco Antônio Bento $^{7}$ Manoela Drews de Aguiar ${ }^{8}$ \\ Aline Pereira $\mathrm{Cruz}^{9}$

\section{RESUMO}

O presente estudo objetivou verificar a relação entre a organização da comunidade arbórea e variáveis ambientais em um fragmento de Floresta Ombrófila Mista. Para isso, na localidade da Coxilha Rica, no planalto sul catarinense, foram alocadas 50 parcelas de $200 \mathrm{~m}^{2} \mathrm{em}$ um fragmento florestal, no qual foram amostrados, medidos (circunferência a altura peito, CAP) e identificados todos os indivíduos arbóreos vivos que apresentaram CAP igual ou superior a $15,7 \mathrm{~cm}$. Em cada parcela, foram obtidas as variáveis ambientais: topografia, cobertura do dossel e características químicas e físicas dos solos. Foram calculados os estimadores fitossociológicos e ordenadas as parcelas em função da abundância das espécies, por meio da análise NMDS (Nonmetric multidimensional scalling). Em seguida, foi realizado ajuste entre a ordenação produzida e as variáveis ambientais, com as variáveis significativas $(p \leq 0,01)$ plotadas na forma de vetores. Foram amostrados 1.447 indivíduos, distribuídos em 69 espécies. Myrcia guianensis (Aubl.) DC. foi a espécie de maior valor de importância $(\mathrm{VI}=10,43 \%)$. Nas áreas com terreno mais declivoso, com maiores cotas altimétricas médias e com solos menos férteis, com maiores teores de MO, Al e Na, destacou-se a presença, entre outras espécies, de Drimys brasiliensis Miers. Nas áreas com o terreno mais plano e solos com maior fertilidade e menores teores de MO, Al e Na, foi comum Sebastiania commersoniana (Baill.) L.B. Sm. \& Downs. Conclui-se que a topografia e as características químicas dos solos foram determinantes para a heterogeneidade florístico-estrutural no fragmento estudado.

Palavras-chave: Floresta Ombrófila Mista; NMDS; variáveis edáficas.

\section{ABSTRACT}

The present study aimed to verify the relationships between tree species organization and environmental

1 Engenharia Florestal, Departamento de Engenharia Florestal, Universidade do Estado de Santa Catarina, Av. Luiz de Camões, 2090, CEP 88520-000, Lages (SC), Brasil.roni_ansolin@yahoo.com.br

2 Engenheira Florestal, Dr ${ }^{\mathrm{a}}$., Professora do Departamento de Engenharia Florestal, Universidade do Estado de Santa Catarina, Av. Luiz de Camões, 2090, CEP 88520-000, Lages (SC), Brasil. carol_sil4@yahoo.com.br

3 Engenheiro Florestal, Dr., Professor do Departamento de Engenharia Florestal, Universidade do Estado de Santa Catarina, Av. Luiz de Camões, 2090, CEP 88520-000, Lages (SC), Brasil. higuchip@gmail.com

4 Engenheira Florestal, Departamento de Engenharia Florestal, Universidade do Estado de Santa Catarina, Av. Luiz de Camões, 2090, CEP 88520-000, Lages (SC), Brasil. larissakuster1@hotmail.com

5 Engenheiro Florestal, Msc., Departamento de Engenharia Florestal, Universidade do Estado de Santa Catarina, Av. Luiz de Camões, 2090, CEP 88520-000, Lages (SC), Brasil. tiagoferreira@florestal.eng.br

6 Engenheiro Florestal, Departamento de Engenharia Florestal, Universidade do Estado de Santa Catarina, Av. Luiz de Camões, 2090, CEP 88520-000, Lages (SC), Brasil. buzzifjr@hotmail.com

7 Engenharia Florestal, Departamento de Engenharia Florestal, Universidade do Estado de Santa Catarina, Av. Luiz de Camões, 2090, CEP 88520-000, Lages (SC), Brasil. marco_a bento@hotmail.com

8 Engenheira Florestal, Msc., Departamento de Engenharia Florestal, Universidade Regional de Blumenau, R. São Paulo, 3250, CEP 89030-000, Blumenau (SC), Brasil. manoo_aguiar@hotmail.com

9 Bióloga, Msc. em Engenharia Florestal, Departamento de Engenharia Florestal, Universidade do Estado de Santa Catarina, Av. Luiz de Camões, 2090, CEP 88520-000, Lages (SC), Brasil. a.line_cruz@yahoo.com.br 
variables in a fragment of Araucaria Forest. To do so, in the locality of Coxilha Rica, in the region called "Planalto Sul Catarinense" region, a total of 50 plots of $200 \mathrm{~m}^{2}$ were allocated in a forest fragment, where all living trees with CAP (circumference at breast height, measured at $1.30 \mathrm{~m}$ above ground) greater than or equal to $15.7 \mathrm{~cm}$ were sampled, measured and identified. Environmental variables related to the terrain, canopy cover and soil chemical and physical properties were obtained for each plot. Phytosociological estimators were calculated and the plots ordinated in function of species abundance by NMDS analyze (Nonmetric multidimensional scalling). Then, the environmental variables were fitted to the produced ordination, being those significant variables $(p \leq 0.01)$ plotted as vectors. A total of 1,447 individuals, distributed in 69 species were sampled. Myrcia guianensis (Aubl.) DC. was the most relative important species (10.43\% of IV). Drimys brasiliensis Miers stood out in steeper areas, with higher elevation and with less fertile soils, with greater values of OM, Al and Na. Sebastiania commersoniana (Baill.) LB Sm \& Downs and others stood out in flat areas, with more fertile soils and low content of OM, Al and $\mathrm{Na}$. We concluded that terrain and soil chemical properties represent an important source of floristic-structural heterogeneity in the study fragment.

Keywords: Araucaria Forest; NMDS; edaphic variables.

\section{INTRODUÇÃO}

Avegetação natural da região do planalto sulcatarinense destaca-se pela presença de um mosaico constituído por campos naturais e florestas. Enquanto os campos, classificados como Estepe GramíneoLenhosa, segundo o IBGE (2012), representam um tipo vegetacional remanescente de períodos glaciais (BEHLING et al., 2004), as florestas, com Araucaria angustifolia (Bertol.) Kuntze. como elemento mais característico, ocorrem na forma de fragmentos naturais de Floresta Ombrófila Mista (FOM). Apesar de sua grande importância ecológica, em função de sua elevada diversidade de espécies e endemismo e de abrigar nascentes de importantes rios (e.g., Pelotas, Canoas), além de banhados e turfeiras, atualmente esta região está sujeita à intensa pressão de origem antrópica, caracterizada pela expansão de áreas de monoculturas florestais, construções de usinas hidrelétricas e atividades agropecuárias (BOLDRINI, 2009). Neste sentido, estudos em áreas florestais, que contribuam para o conhecimento da diversidade regional e a ecologia de espécies arbóreas, são relevantes para permitir inferências sobre possíveis impactos ambientais e subsidiar estratégias de conservação e restauração.

Esforços recentes têm permitido um maior conhecimento sobre a caracterização florísticaestrutural de remanescentes florestais regionais (e.g. KLAUBERG et al., 2010; NASCIMENTO et al., 2011; NEGRINI et al., 2012; SILVA et al., 2012a; GASPER et al., 2013; NEGRINI et al., 2014). Apesar da dominância de Araucaria angustifolia, que imprime um aspecto homogêneo nesta fitofisionomia, regionalmente existe uma elevada substituição de espécies, em função, principalmente, da altitude (HIGUCHI et al., 2012a). No entanto, poucos estudos foram realizados com o propósito de avaliar a influência de gradientes ambientais em pequenas escalas espaciais. Como os poucos exemplos no Planalto Sul-Catarinense, podem ser citados os trabalhos de Higuchi et al. (2012b), na localidade de Pedras Brancas no município de Lages, Higuchi et al. (2013), no município de Painel, e Higuchi et al. (2014), também em Lages, que demonstraram a importância de variáveis edáficas e do relevo sobre a organização de comunidades de espécies arbóreas. Assim, a realização de um maior número de estudos com esta abordagem é importante, pois pode contribuir para inferências mais consistentes sobre a relação entre espécies $\mathrm{x}$ ambiente em fragmentos florestais.

Desta forma, o presente estudo teve como objetivo principal contribuir para o conhecimento ecológico de remanescentes florestais em uma região com predomínio do mosaico campo-floresta. Para isto, foi escolhida uma área na região da Coxilha Rica, localizada no município de Lages, na divisa com o estado do RS. Esta região apresenta mais de $100 \mathrm{~km}$ de extensão, com uma formação geológica da Serra Geral, com cerca de 60 milhões de anos, e altitudes que variam de 750 a $1.200 \mathrm{~m}$ (ISRAEL, 2006). Na área de estudo foi verificado se a composição florístico-estrutural do componente arbóreo e a distribuição espacial das espécies estão relacionadas com atributos ambientais do ecossistema, além de determinar quais variáveis ambientais influenciam nos padrões encontrados. 


\section{MATERIAL E MÉTODOS}

O estudo foi realizado em um fragmento florestal localizado na região da Coxilha Rica, no município de Lages - SC. O ponto central do fragmento encontra-se nas coordenadas de latitude $28^{\circ} 07^{\prime} 15^{\prime \prime} \mathrm{S}$ e longitude $50^{\circ} 18^{\prime} 25^{\prime \prime} \mathrm{W}$. O clima predominante é $\mathrm{Cfb}$, segundo a classificação de Köppen. De acordo com a estação meteorológica de Lages, administrada pela EPAGRI/CIRAM/ INMET, a precipitação anual média é de $1.682,80$ $\mathrm{mm}$, com chuvas bem distribuídas no ano, e a temperatura anual média é de $15,9^{\circ} \mathrm{C}$. A altitude no fragmento é de aproximadamente $1.050 \mathrm{~m} \mathrm{e}$ a vegetação arbórea é classificada, pelo IBGE (2012), como Floresta Ombrófila Mista. A floresta é bastante heterogênea por possuir diferentes micro-habitat. Como grande parte dos fragmentos da região, que possui elevado número de nascentes, este possui cursos d'água de pequeno porte em seu interior, o que ocasiona trechos de vegetação sob influência desses cursos. Assim, as condições edáficas também são distintas, com solos distróficos e ácidos que variam desde aqueles classificados como Gleissolos, nos trechos mais úmidos, até Cambissolos, nas áreas mais bem drenadas. O histórico da área foi de corte seletivo no passado, durante o "Ciclo da Araucária", especialmente entre as décadas de $50 \mathrm{e}$ 70. Atualmente, o fragmento é protegido e encontrase em estágio de sucessão avançada.

Para o levantamento da composição florístico-estrutural, foram alocadas 50 parcelas de $10 \times 20$ m (Figura 1), distribuídas sistematicamente, distanciadas $5 \mathrm{~m}$ entre si, em sete transeções, totalizando 1 ha de área amostrada. Esta amostragem se deu em função do objetivo do presente trabalho, que foi de analisar a influência de atributos ambientais sobre a organização da comunidade e distribuição de espécies arbóreas. Assim, considerando a importância da topografia, condicionante de características edáficas, e do efeito de borda sobre o componente arbóreo, o local, o direcionamento e o comprimento de cada transeção foram definidos em campo, em pontos do remanescente em que havia um gradiente topográfico evidente, buscando também contemplar a variação de borda e interior. Em cada parcela, todos os indivíduos arbóreos vivos que apresentaram CAP (circunferência a altura do peito, medida a $1,30 \mathrm{~m}$ acima do solo) igual ou superior a $15,7 \mathrm{~cm}$ foram identificados e mensurados
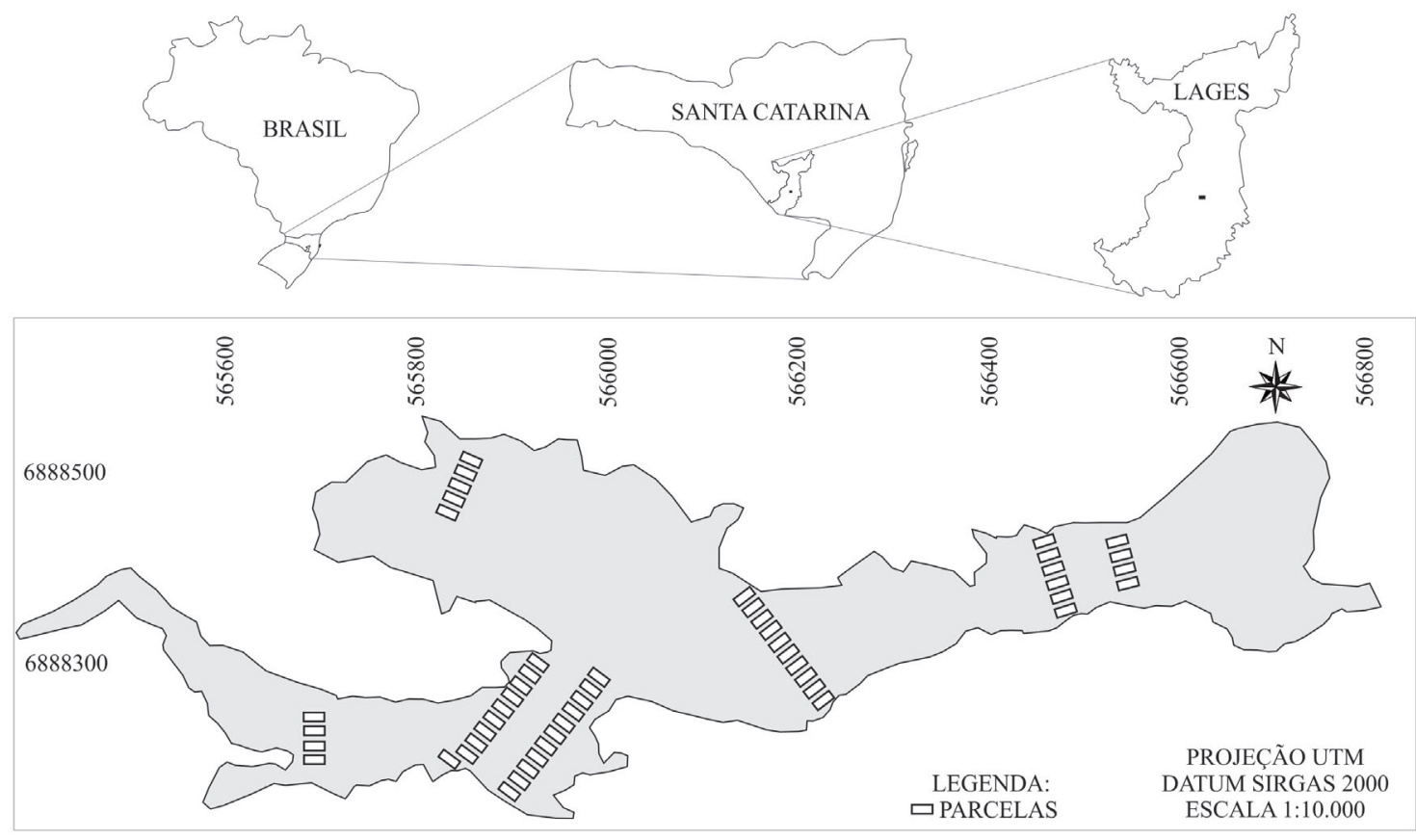

FIGURA 1: Localização geográfica e distribuição das parcelas no fragmento de Floresta Ombrófila Mista na Coxilha Rica em Lages - SC.

FIGURE 1: Geographic location and plots distribution in an Araucaria Forest fragment in Coxilha Rica, in the municipality of Lages, SC state. 
(CAP). Indivíduos arbóreos com troncos múltiplos foram inventariados quando a raiz da soma dos quadrados dos CAP foi maior ou igual a $15,7 \mathrm{~cm}$. As identificações foram realizadas por meio de literatura e consulta a especialistas. As espécies de angiospermas foram classificadas nas famílias de acordo com o sistema APG III (ANGIOSPERM PHYLOGENY GROUP III, 2009).

Realizou-se o levantamento das seguintes variáveis ambientais em cada parcela: topografia, cobertura do dossel e características químicas e físicas dos solos. O levantamento topográfico foi realizado com auxílio de trena, bússola, clinômetro e GPS, nos quais foram definidas três variáveis por parcela: cota média $(\mathrm{m})$, desnível máximo (m) e declividade média $\left(^{\circ}\right.$ ) (OLIVEIRA FILHO et al., 1994; VAN DEN BERG; OLIVEIRA FILHO, 1999). A avaliação da cobertura do dossel foi realizada por meio da média, por parcela, de quatro leituras, na direção norte, sul, leste e oeste, no centro da parcela, utilizando um densiômetro esférico (modelo A) côncavo (LEMMON, 1956), no mês de outubro de 2012. As propriedades químicas e físicas dos solos de cada parcela foram obtidas por meio da análise de amostras compostas superficiais, provenientes de quatro coletas distribuídas em cada parcela, a profundidade 0 a 20 $\mathrm{cm}$. As amostras foram enviadas para o Laboratório de Solos do Centro de Ciências Agroveterinárias da Universidade do Estado de Santa Catarina (CAV/ UDESC) para análises químicas e físicas, de acordo com os métodos descritos pela EMBRAPA (1997). As variáveis químicas mensuradas foram o $\mathrm{pH}$ em $\mathrm{H}_{2} \mathrm{O}$; os teores de alumínio ( $\mathrm{Al}$ ), matéria orgânica $(\mathrm{MO})$, cálcio $(\mathrm{Ca})$, magnésio $(\mathrm{Mg})$, fósforo $(\mathrm{P})$, potássio $(\mathrm{K})$ e sódio $(\mathrm{Na})$; e os cálculos da CTC efetiva $(\mathrm{CTC}$ a pH $=7,0)$ e da saturação por base $(\mathrm{V})$. As variáveis físicas dos solos foram as porcentagens de areia, silte e argila.

Com o objetivo de verificar a eficácia da amostragem realizada para a obtenção da riqueza de espécies, foi gerada uma curva de acumulação de espécies, por meio do método de permutação $(\mathrm{n}=999)$ (HELTSHE; FORRESTER, 1983). Para as populações encontradas, foram calculados os estimadores fitossociológicos: densidade, dominância, frequência e valor de importância (média da densidade, dominância e frequência relativa) de cada espécie, conforme metodologia desenvolvida por Mueller-Dombois e Ellenberg (1974). Foi realizada a ordenação das parcelas em função da abundância das espécies, por meio da análise multivariada NMDS (Nonmetric multidimensional scalling) e plotadas, a posteriori, as variáveis ambientais significativas $(p \leq 0,01)$ no diagrama de ordenação. A verificação da adequabilidade da ordenação foi feita por meio do valor de stress. As análises dos dados foram feitas no programa estatístico R (R DEVELOPMENT CORE TEAM, 2014), com a utilização do pacote Vegan (OKSANEN et al., 2014) para a NMDS.

\section{RESULTADOS E DISCUSSÃO}

Foram amostrados 1.447 indivíduos (Tabela 1), distribuídos em 28 famílias, 46 gêneros e 69 espécies arbóreas. A suficiência da amostragem para determinação da riqueza de espécies, apesar da elevada heterogeneidade ambiental encontrada, foi alcançada, pois a curva de acumulação de espécies tendeu à estabilização (Figura 2). De acordo com Kersten e Galvão (2011), atinge-se a suficiência quando a linha tende à estabilidade e o aumento do esforço amostral não altera significativamente o número de espécies observadas. Assim, os autores sugerem que um aumento de $10 \%$ na área amostral resulte em aumento inferior a $5 \%$ no número de espécies. Com a inclusão da quinquagésima parcela, que correspondeu a $2 \%$ da área amostral, poderia haver aumento de até $1 \%$ em espécies. Como o aumento foi de $0,58 \%$, conclui-se que a maior parte da riqueza de espécies arbóreas foi amostrada.

A família Myrtaceae se destacou com a maior riqueza (19 espécies). A elevada riqueza de Myrtaceae entre as espécies arbóreas em FOM na região também foi observada por Klauberg et al. (2010), Nascimento et al. (2011), Higuchi et al. (2012a), Higuchi et al. (2012b), Negrini et al. (2012) e Silva et al. (2012a), consolidando um padrão para esta formação florestal. Porém, a riqueza total das espécies encontrada (69) é menor do que a de outros estudos na mesma faixa altitudinal e que tiveram a mesma área amostrada e o mesmo critério de inclusão (e.g. Silva et al. (2012a), encontraram 87 espécies e Higuchi et al. (2012b), 92 espécies). Esta variação na riqueza local pode estar relacionada com diferenças ambientais que, no caso do presente estudo, provavelmente é devido à presença de trechos alagados observados próximos a pequenos corpos d'água, no interior do fragmento. Ambientes com excesso hídrico são limitantes e frequentemente resultam em menor riqueza de espécies (SILVA et al., 2012b).

Em relação à estrutura horizontal da 
floresta, as famílias mais abundantes em número de indivíduos foram Myrtaceae, com 522 árvores amostradas, seguida por Euphorbiaceae, com
199, e Araucariaceae, com 122. As espécies com os maiores valores de importância (VI) foram: Myrcia guianensis (Aubl.) DC. (família

TABELA 1: Estimadores fitossociológicos das 30 espécies de maior valor de importância (VI) presentes em um fragmento de Floresta Ombrófila Mista na Coxilha Rica em Lages - SC, ordenadas de forma decrescente pelo VI.

TABLE 1: Phytosociological estimators of 30 species of greatest of importance values (VI) in an Araucaria Forest fragment in Coxilha Rica, Lages, Santa Catarina state, southern Brazil, sorted in descending order of VI.Em que: DA = densidade absoluta, em número de indivíduos; DR = densidade relativa $(\%)$; DoA $=$ dominância absoluta $\left(\mathrm{m}^{2} / \mathrm{ha}\right) ; \mathrm{DoR}=$ dominância relativa $(\%)$; $\mathrm{FA}=$ frequência absoluta $(\%) ; \mathrm{FR}=$ frequência relativa $(\%) ; \mathrm{VI}=$ valor de importância $(\%)$.

\begin{tabular}{|c|c|c|c|c|c|c|c|}
\hline Espécies & DA & DR & DoA & DoR & FA & FR & VI \\
\hline Myrcia guianensis (Aubl) DC. & 158 & 10,92 & 5,1383 & 13,87 & 84 & 6,52 & 10,44 \\
\hline \multirow{2}{*}{$\begin{array}{l}\text { Araucaria angustifolia (Bertol.) Kuntze } \\
\text { Sebastiania commersoniana (Baill.) L.B. Sm. \& } \\
\text { Downs }\end{array}$} & 122 & 8,43 & 4,3105 & 11,64 & 80 & 6,21 & 8,76 \\
\hline & 110 & 7,60 & 4,6075 & 12,44 & 66 & 5,12 & 8,39 \\
\hline Lithrea brasiliensis Marchand & 85 & 5,87 & 3,7060 & 10,00 & 72 & 5,59 & 7,16 \\
\hline Calyptranthes concinna DC. & 151 & 10,44 & 1,8158 & 4,90 & 74 & 5,75 & 7,03 \\
\hline Ocotea pulchella (Nees) Mez & 30 & 2,07 & 3,3487 & 9,04 & 46 & 3,57 & 4,89 \\
\hline Cinnamodendron dinisii Schwanke & 59 & 4,08 & 1,8297 & 4,94 & 62 & 4,81 & 4,61 \\
\hline Scutia broxifolia Reissek & 73 & 5,04 & 0,7845 & 2,12 & 74 & 5,75 & 4,30 \\
\hline Myrcianthes gigantea (D. Legrand) D. Legrand & 52 & 3,59 & 1,3510 & 3,65 & 58 & 4,50 & 3,91 \\
\hline Sebastiania brasiliensis (Spreng.) Müll.Arg. & 89 & 6,15 & 0,5250 & 1,42 & 52 & 4,04 & 3,87 \\
\hline Drimys brasiliensis Miers & 62 & 4,28 & 0,7234 & 1,95 & 42 & 3,26 & 3,17 \\
\hline Casearia decandra Jacq. & 54 & 3,73 & 0,7439 & 2,01 & 46 & 3,57 & 3,10 \\
\hline \multirow{2}{*}{$\begin{array}{l}\text { Cinnamomum anoenum (Nees) Kosterm. } \\
\text { Allophylus edulis (A.St.-Hil., Cambess. \& A. Juss.) } \\
\text { Radlk. }\end{array}$} & 23 & 1,59 & 1,1732 & 3,17 & 32 & 2,48 & 2,41 \\
\hline & 29 & 2,00 & 5 & 1,66 & 36 & 2,80 & 2,15 \\
\hline Clethra scabra Pers. & 23 & 1,59 & 0,9411 & 2,54 & 26 & 2,02 & 2,05 \\
\hline Symplocos uniflora (Pohl) Benth. & 33 & 2,28 & 0,2955 & 0,80 & 30 & 2,33 & 1,80 \\
\hline \multirow{2}{*}{$\begin{array}{l}\text { Acca sellowiana (O.Berg) Burret } \\
\text { Myrceugenia cf. glaucescens (Cambess.) D.Legrand } \\
\text { \& Kausel }\end{array}$} & 30 & 2,07 & 0,1951 & 0,53 & 36 & 2,80 & 1,80 \\
\hline & 30 & 2,07 & 0,3123 & 0,84 & 24 & 1,86 & 1,59 \\
\hline Ilex theezans Mart. ex Reissek & 16 & 1,11 & 0,6149 & 1,66 & 24 & 1,86 & 1,54 \\
\hline \multirow{2}{*}{$\begin{array}{l}\text { Blepharocalyx salicifolius (Kunth) O.Berg } \\
\text { Myrceugenia mesomischa (Burret) D. Legrand et } \\
\text { Kausel }\end{array}$} & 21 & 1,45 & 0,3338 & 0,90 & 24 & 1,86 & 1,41 \\
\hline & 24 & 1,66 & 0,1 & 0,32 & 22 & 1,71 & 1,23 \\
\hline Myrrhinium atropurpureum Schott & 16 & 1,11 & 0,1117 & 0,30 & 22 & 1,71 & 1,04 \\
\hline Zanthoxylum rhoifolium Lam. & 11 & 0,76 & 0,2882 & 0,78 & 20 & 1,55 & 1,03 \\
\hline Dasyphyllum brasiliense (Spreng.) Cabrera & 13 & 0,90 & 0,1570 & 0,42 & 20 & 1,55 & 0,96 \\
\hline Myrcia laruotteana Cambess & 12 & 0,83 & 0,0985 & 0,27 & 20 & 1,55 & 0,88 \\
\hline Mimosa scabrella Benth. & 7 & 0,48 & 0,3226 & 0,87 & 10 & 0,78 & 0,71 \\
\hline Myrsine coriacea $(\mathrm{Sw}.) \mathrm{R} . \mathrm{Br}$. & 9 & 0,62 & 0,0807 & 0,22 & 16 & 1,24 & 0,69 \\
\hline Xylosma ciliatifolia (Clos) Eichler & 8 & 0,55 & 0,0659 & 0,18 & 14 & 1,09 & 0,61 \\
\hline Nectandra megapotamica (Spreng.) Mez & 4 & 0,28 & 0,3920 & 1,06 & 6 & 0,47 & 0,60 \\
\hline Ilex microdonta Reissek & 5 & 0,35 & 0,2269 & 0,61 & 10 & 0,78 & 0,58 \\
\hline Outras & 88 & 6,13 & 1,8184 & 4,92 & - & 10,95 & 7,3 \\
\hline Total geral & 1447 & 100 & 37,04 & 100 & - & 100 & 100 \\
\hline
\end{tabular}




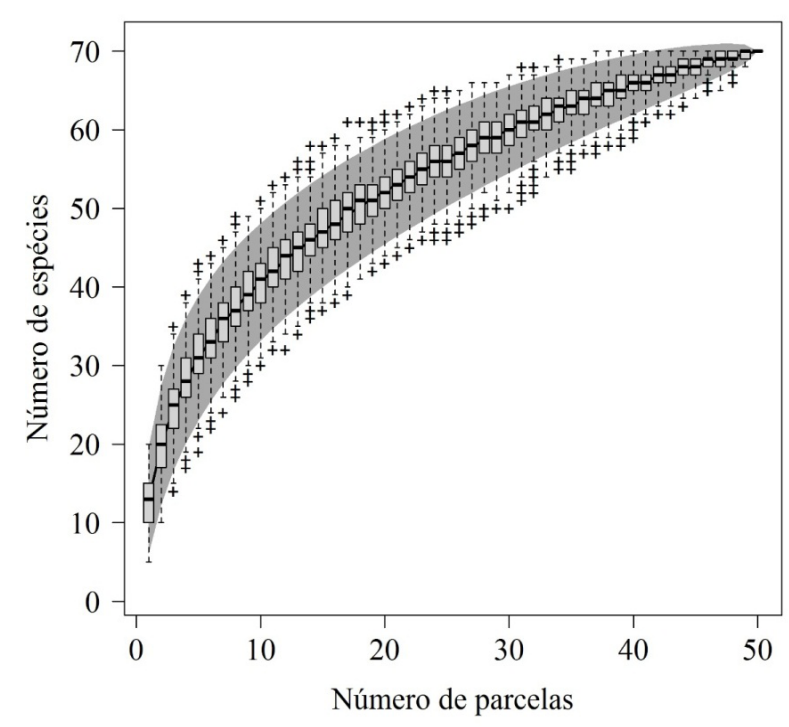

FIGURA 2: Curva de acumulação de espécies para a amostragem realizada em um fragmento de Floresta Ombrófila Mista na localidade da Coxilha Rica em Lages - SC.

FIGURE 2: Species accumulation curve for the sampling conducted in an Araucaria Forest fragment, in Coxilha Rica, Lages, Santa Catarina state, southern Brazil.

Myrtaceae) (VI = 10,44\%), Araucaria angustifolia (Bertol.) Kuntze (Araucariaceae) (VI = 8,76\%) e Sebastiania commersoniana (Baill.) L.B. Sm. \& Downs. (Euphorbiaceae) $(\mathrm{VI}=8,39 \%$ ) (Tabela 1). Essas espécies se destacaram devido às suas elevadas abundâncias de indivíduos (DA de 110 a 158 ind./ha), altos valores de dominâncias (DoA de 4,31 a $5,14 \mathrm{~m}^{2} / \mathrm{ha}$ ) e ocorrência na maioria das parcelas (FA de 66 a 84\%). Outras espécies, como Calyptranthes concinna DC. (Myrtaceae), por exemplo, apesar de sua elevada abundância (DA = 151 ind./ha) e frequência ( $\mathrm{FA}=74 \%)$, não esteve entre as três espécies de maior VI $(\mathrm{VI}=7,03)$ por apresentar indivíduos de menor porte (DoA $=1,82$ $\mathrm{m}^{2} / \mathrm{ha}$ ). Além da elevada participação de Myrtaceae e Araucaria angustifolia, padrão típico na FOM, destaca-se a grande participação de Sebastiania commersoniana, com 110 indivíduos amostrados. Esta é uma espécie característica de florestas inundáveis (SILVA et al., 2007), confirmando o padrão da presente floresta, que possui trechos sob alagamento.

A área apresentou cota média de 1.074,66 $\mathrm{m}$ (Tabela 2), com elevada variação no terreno, com parcelas com topografia plana $\left(0,5^{\circ}\right)$ até forte ondulada $\left(22,25^{\circ}\right)$, segundo a classificação do IBGE (2007). A cobertura do dossel apresentou valor médio de $91,72 \%$, que indica que baixa radiação lumínica chega até o solo da floresta, o que pode influenciar a regeneração natural e a dinâmica da comunidade. Esse valor é próximo ao encontrado em outros estudos em FOM bem-conservadas, como de Higuchi et al. (2012b) (87,20\%), que utilizaram o mesmo método de mensuração. Porém, Medri et al. (2009), também com o mesmo método utilizado, encontram valor menor em fragmento secundário na FOM $(60 \%)$, possivelmente devido à maior abertura do dossel em florestas secundárias.

Em relação às características do solo, o valor de $\mathrm{pH}$ variou de 4,20 a 5,70, com valor médio de 4,70, sendo os solos classificados, segundo Tomé Júnior (1997), como de acidez alta. Os valores encontrados para $\mathrm{Al}$ variaram de 0 a $7,43 \mathrm{cmolc} /$ $\mathrm{dm}^{3}$, obtendo-se valor médio de $3,30 \mathrm{cmolc} / \mathrm{dm}^{3}$, valor alto, segundo a classificação de Alvarez et al. (1999). O excesso de íons de alumínio normalmente resulta em toxicidade para muitas espécies de plantas (HARIDASAN; ARAÚJO, 2005). O teor de matéria orgânica variou entre 2,70 a $11,80 \%$, com valor médio de $5,46 \%$, valor menor que os encontrados por Higuchi et al. (2012b, M.O. = 8,11\%) em FOM da região, portando, indicando que não há excesso de matéria orgânica no solo. Os teores de $\mathrm{Ca}, \mathrm{Mg}$ e $\mathrm{K}$ foram relativamente altos $\left(4,10 \mathrm{cmolc} / \mathrm{dm}^{3}\right.$, $1,75 \mathrm{cmolc} / \mathrm{dm}^{3}$ e $88,26 \mathrm{mg} / \mathrm{dm}^{3}$, respectivamente), segundo a classificação de Alvarez et al. (1999), e o teor de $\mathrm{P}\left(6,54 \mathrm{mg} / \mathrm{dm}^{3}\right)$ foi relativamente baixo, segundo esses autores. Também o valor de Na médio, de $20,54 \mathrm{mg} / \mathrm{dm}^{3}$, pode ser considerado elevado se comparado ao de Higuchi et al. (2012b) $(\mathrm{Na}=2,24$ $\left.\mathrm{mg} / \mathrm{dm}^{3}\right)$. Porém, apesar dos altos teores de alguns nutrientes, a CTC efetiva obteve valores entre 4,15 a $17,61 \mathrm{cmolc} / \mathrm{dm}^{3}$ e valor médio de $9,27 \mathrm{cmolc} /$ $\mathrm{dm}^{3}$, valor inferior ao encontrado por Higuchi et al. (2012b) $\left(23,66 \mathrm{cmolc} / \mathrm{dm}^{3}\right)$, e a saturação de base variou entre 1,81 a $66,16 \%$, com média de $21,95 \%$, também valor inferior ao encontrado por Higuchi et al. (2012b) (44,61\%). Considerando-se a saturação de bases, pode-se classificar o solo do fragmento como distrófico $(\mathrm{V}<50 \%)$, ou seja, há limitações na disponibilidade de alguns nutrientes, especialmente o fósforo.

Com relação à textura, os valores médios encontrados para argila, silte e areia foram 21,84 $\%, 49,86 \%, 28,40 \%$, respectivamente. Assim, de acordo com a EMBRAPA (2006), o solo pode ser classificado como de textura franco-arenosa, 
TABELA 2: Valores médios de todas as variáveis ambientais analisadas em 50 parcelas alocadas no fragmento estudado de Floresta Ombrófila Mista na Coxilha Rica em Lages - SC.

TABLE 2: Mean values of all environmental variables analyzed within 25 plots allocated in an Araucaria Forest fragment in Coxilha Rica, Lages, SC state.

\begin{tabular}{|c|c|}
\hline Variáveis ambientais & Média \\
\hline Cota média (m) & $1.074,66( \pm 13,15)$ \\
\hline Desnível máximo (m) & $3,25( \pm 2,72)$ \\
\hline Declividade média (graus) & $6,41( \pm 5,87)$ \\
\hline Cobertura do dossel (\%) & $91,72( \pm 6,90)$ \\
\hline $\mathrm{pH} \mathrm{H}_{2} \mathrm{O}$ & $4,70( \pm 0,27)$ \\
\hline $\mathrm{Al}\left(\mathrm{cmolc} / \mathrm{dm}^{3}\right)$ & $3,30( \pm 1,98)$ \\
\hline $\mathrm{MO}(\%)$ & $5,46( \pm 1,92)$ \\
\hline $\mathrm{Ca}\left(\mathrm{cmolc} / \mathrm{dm}^{3}\right)$ & $4,10( \pm 2,77)$ \\
\hline $\mathrm{Mg}\left(\mathrm{cmolc} / \mathrm{dm}^{3}\right)$ & $1,75( \pm 1,08)$ \\
\hline $\mathrm{P}\left(\mathrm{mg} / \mathrm{dm}^{3}\right)$ & $6,54( \pm 1,74)$ \\
\hline $\mathrm{K}\left(\mathrm{mg} / \mathrm{dm}^{3}\right)$ & $88,26( \pm 42,67)$ \\
\hline $\mathrm{Na}\left(\mathrm{mg} / \mathrm{dm}^{3}\right)$ & $20,54( \pm 10,29)$ \\
\hline CTC efetiva $\left(\mathrm{cmolc} / \mathrm{dm}^{3}\right)$ & $9,27( \pm 2,96)$ \\
\hline Saturação por base (V, em \%) & $21,95( \pm 14,23)$ \\
\hline Teor de areia $(\%)$ & $28,40( \pm 10,68)$ \\
\hline Teor de silte $(\%)$ & $49,86( \pm 8,07)$ \\
\hline Teor de argila $(\%)$ & $21,84( \pm 6,24)$ \\
\hline
\end{tabular}

Em que: Os valores entre parênteses referem-se ao desvio padrão.

que são, geralmente, aqueles que possuem baixa disponibilidade de reter nutrientes, como confirmado pela classificação como distrófico.

Dessa forma, pode-se caracterizar o ambiente como sendo muito variável em topografia, mas com dossel fechado e com solos arenosos distróficos ácidos e álicos. Porém, a elevada variação do terreno que, em geral, também influencia nas condições edáficas, resultou em um ambiente com uma comunidade de espécies arbórea heterogênea em pequena escala espacial, conforme indicado pela NMDS (Figura 3). Esta obteve valor de estresse baixo $(19,6 \%)$. Considerando que o estresse varia de 0 a $100 \%$, o baixo valor encontrado indica que os diagramas de ordenação são adequados para interpretação, uma vez que demonstra um bom ajuste linear entre as distâncias euclidianas das projeções das parcelas na ordenação e a similaridade florístico-estrutural entre elas (BORCARD et al., 2011).

Espécies como Drimys brasiliensis Miers,
Ilex microdonta Reissek e Casearia obliqua Spreng. foram mais abundantes nas parcelas com relevo mais acidentado (maior cota, desnível e declividade) e solos com maiores teores de $\mathrm{MO}, \mathrm{Al}$ e Na. Higuchi et al. (2013), estudando uma FOM Alto-Montana na região, relataram a ocorrência de Drimys brasiliensis relacionado a locais mais declivosos, podendo a espécie estar associada a solos menos profundos. Apesar da maior declividade, esse trecho, provavelmente, apresenta menor seletividade ambiental, pois não possui áreas alagáveis, como nos trechos planos, podendo comportar as espécies exclusivas de ambientes bem drenados.

Sebastiania commersoniana (Baill.) L.B. Sm. \& Downs, Allophylus edulis (A.St.-Hil., Cambess. \& A. Juss.) Radlk., Myrsine coriacea (Sw.) R.Br., Myrcianthes pungens (O.Berg) D. Legrand, Campomanesia xanthocarpa O.Berg, entre outras, foram comuns nas áreas com maiores teores de saturação por bases, menor declividade, menores teores de $\mathrm{MO}, \mathrm{Al}$ e $\mathrm{Na}$, e que possuíam 
trechos inundados. Alguns padrões ambientais encontrados, apesar de apresentarem relações negativas pouco comuns, como o de teor de matéria orgânica e a saturação por bases, são padrões observados em outros estudos na região, como o de Marcon et al. (2014), que também verificaram maior teor de matéria orgânica em ambiente com menor saturação por bases. Devido à grande variação de influências ambientais em cada micro-habitat distinto, muitas das quais difíceis de mensurar, é comum, em florestas naturais, a ocorrência dos mais distintos padrões ambientais. Em relação às espécies encontradas nesse micro-habitat, estudos realizados por Araujo (2010) demonstraram que Sebastiania commersoniana, Allophylus edulis e Myrcianthes pungens estiveram mais associadas a sítios próximos de cursos d'água, com menor declividade e maior profundidade do solo. Scipioni et al. (2010) encontraram Myrcianthes pungens associada a locais com maior disponibilidade de cátions, em posições inferiores e intermediárias do terreno, com diferentes níveis de declividade.

Esses padrões, com a ocorrência frequente de espécies em determinado micro-habitat na floresta, associadas a características topográficas e químicas do solo, pode auxiliar na definição de áreas prioritárias para a conservação e em programas de recuperação de florestas degradadas. Em um ambiente heterogêneo, é necessária a preservação de todo o conjunto de micro-habitat, a fim de se contemplar toda a comunidade.

De acordo com os ajustes das variáveis ambientais na ordenação produzida pela NMDS, as espécies de maior importância relativa na comunidade, Myrcia guianensis e Araucaria angustifolia, não ocorreram nos extremos ambientais analisados. Esse padrão pode indicar suas maiores abundâncias em condições ambientais intermediárias ou uma ampla distribuição no fragmento estudado, conforme já sugerido pela elevada frequência relativa das espécies. Estudos a respeito da autoecologia dessas espécies são necessários para inferências mais seguras a respeito de suas preferências.

\section{CONCLUSÕES}

O fragmento estudado apresentou composição florística-estrutural com elevada participação da família Myrtaceae e abundância de Araucaria angustifolia, porém, com menor riqueza em relação ao padrão regional para este tipo de floresta. Em escala local, verificou-se heterogeneidade florístico-estrutural associada a variações topográficas no terreno e propriedades químicas do solo, que indicaram dois micro-habitat distintos: um deles em maior cota e declividade, com solos com menor saturação por bases, e outro em locais mais baixos e com maior influência hídrica, menor declividade e maior saturação por bases.

\section{AGRADECIMENTOS}

A Universidade do Estado de Santa Catarina, pela concessão da bolsa ao primeiro

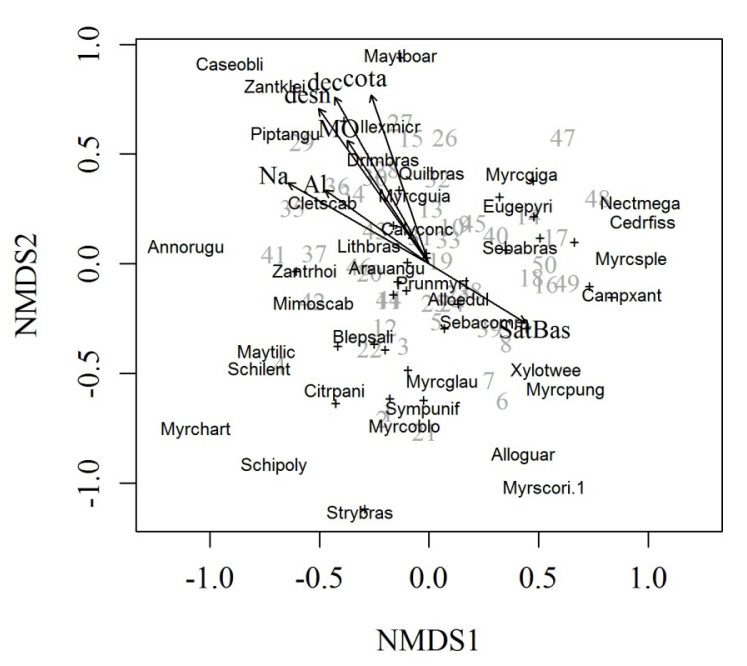

FIGURA 3: Diagrama de ordenação das parcelas e espécies juntamente com os vetores das variáveis ambientais significativas ( $p$ $\leq 0,01$ ) produzido pela análise NMDS (Escalonamento multidimensional não métrico) no fragmento estudado de Floresta Ombrófila Mista na Coxilha Rica em Lages - SC. Cota $=$ cota média; dec = declividade; $\mathrm{MO}$ $=$ matéria orgânica; desn $=$ desnível máximo; $\mathrm{Al}=$ Alumínio; $\mathrm{Na}=$ sódio; SatBas $=$ saturação por base.

FIGURE 3: Ordination diagrams produced by NMDS (Nonmetric multidimensional scaling) analysis for plots with vectors of environmental variables $(\mathrm{p}<0.01)$ in Coxilha Rica, Lages, Santa Catarina state, southern Brazil. Cota $=$ mean altitude; dec $=$ declivity $\mathrm{MO}=$ organic matter; desn = altitude level difference; $\mathrm{Al}=$ Aluminum; $\mathrm{Na}=$ sodium; SatBas $=$ base saturation. 
autor do trabalho. À Lucia Bianchini de Ávila, por ter permitido que o estudo fosse realizado em sua propriedade. Ao Dr. Marcos Eduardo Guerra Sobral, pela identificação das espécies de Myrceugenia spp.

\section{REFERÊNCIAS BIBLIOGRÁFICAS}

ALVAREZ, V. V. H. et al. Interpretação dos resultados das análises de solo. In: RIBEIRO, A. C. et al. (Orgs.). Recomendações para uso de corretivos e fertilizantes em Minas Gerais. Viçosa: Comissão de Fertilidade do Solo do Estado de Minas Gerais, 1999. 359 p.

ARAUJO, A. C. B. Efeito do pastoreio de bovinos sobre a estrutura da mata ciliar do Arroio Espinilho em Sant'ana do Livramento, RS, Brasil. 2010. 92 f. Dissertação (Mestrado em Engenharia Florestal) - Universidade Federal de Santa Maria, Santa Maria, 2010.

ANGIOSPERM PHYLOGENY GROUP III. An update of the Angiosperm Phylogeny Group classification for the orders and families of flowering plants: APG III. Botanical Journal of the Linnean Society, London, v. 161, n. 2, p. 105-121, 2009.

BEHLING, H. et al. Quaternary Araucaria forest, grassland (Campos), fire and climate dynamics, studied by high-resolution pollen, charcoal and multivariate analysis of the Cambará do Sul core in southern Brazil. Palaeogeography, Palaeoclimatology, Palaeoecology, Amsterdam, v. 203, n. 3-4, p. 277-297, 2004.

BOLDRINI, I. I. Biodiversidade dos campos do planalto das araucárias. Brasília: Ministério do Meio Ambiente, 2009. 240 p.

BORCARD, D. et al. Numerical ecology with $\mathbf{R}$. New York: Springer, 2011. 306 p.

EMBRAPA. Manual de métodos de análises de solo. 2. ed. Rio de Janeiro: Centro Nacional de Pesquisa de Solos, 1997. 247 p.

EMBRAPA. Sistema brasileiro de classificação de solos. 2. ed. Rio de Janeiro: EMBRAPA, 2006. 306 p.

GASPER, A. L. et al. Inventário florístico florestal de Santa Catarina: espécies da Floresta Ombrófila Mista. Rodriguésia, Rio de Janeiro, v. 64, n. 2, p. 201-210, 2013.

HARIDASAN, M.; ARAÚJO, G. M. Perfil nutricional de espécies lenhosas de duas florestas semidecíduas em Uberlândia, MG. Revista Brasileira de Botânica, São Paulo, v. 28, n. 2, p. 295-303, 2005.
HELTSHE, J. F.; FORRESTER, N. E. Estimating species richness using the jackknife procedure. Biometrics, Hoboken, v. 39, n. 1, p. 1-12, 1983.

HIGUCHI, P. et al. Floristic composition and phytogeography of the tree component of Araucaria Forest fragments in southern Brazil. Brazilian Journal of Botany, São Paulo, v. 35, n. 2, p. 145-157, 2012a.

HIGUCHI, P. et al. Influência de variáveis ambientais sobre o padrão estrutural e florístico do componente arbóreo em um fragmento de Floresta Ombrófila Mista Montana, em Lages, SC. Ciência Florestal, Santa Maria, v. 22, n. 1, p. 79-90, 2012b. HIGUCHI, P. et al. Florística e estrutura do componente arbóreo e análise ambiental de um fragmento de Floresta Ombrófila Mista Alto-Montana no município de Painel, SC. Ciência Florestal, Santa Maria, v. 23, n. 1, p. 153-164, 2013.

HIGUCHI, P. et al. Partição espacial de espécies arbóreas em função da drenagem do solo em um fragmento de floresta com araucária no Sul do Brasil. Ciência Florestal, Santa Maria, v. 24, n. 2, p. 421-429, 2014.

IBGE. Manual técnico de pedologia. 2. ed. Rio de Janeiro: IBGE, 2007. 323 p. (Manuais Técnicos em Geociências, n. 4).

IBGE. Manual técnico da vegetação brasileira. Rio de Janeiro: IBGE, 2012. 271 p.

ISRAEL, V. Proteção Jurídica do patrimônio paisagístico - ambiental de interesse cultural: os corredores de tropas de Coxilha Rica, no estado de Santa Catarina. 2006. 89 f. Dissertação (Mestrado em Direito) - Universidade de Caxias do Sul, Caxias do Sul, 2006.

KERSTEN, R. A.; GALVÃO, F. Suficiência amostral em inventários florísticos e fitossociológicos. In: FELFILI, J. M. et al. (Orgs.). Fitossociologia no Brasil: métodos e estudos de casos. Viçosa: Editora UFV, 2011. p. 153-176.

KLAUBERG, C. et al. Florística e estrutura de um fragmento de Floresta Ombrófila Mista no Planalto Catarinense. Biotemas, Florianópolis, v. 23, n. 1, p. 35-47, 2010.

LEMMON, P. A spherical densiometer for estimating forest overstory density. Forest Science, Grosvenor Lane, v. 2, n. 4, p. 314-320, 1956.

MARCON, A. K. et al. Variação florístico-estrutural em resposta à heterogeneidade ambiental em uma Floresta Nebular em Urubici, Planalto Catarinense. Scientia Forestalis, Piracicaba, v. 42, n. 103, p. 439-450, 2014. 
MEDRI, P. S. et al. Comparação de parâmetros bióticos e abióticos entre fragmento de floresta secundária e reflorestamento de Araucaria angustifolia (Bertol.) O. Kuntze. Semina: Ciências Biológicas e da Saúde, Londrina, v. 30, n. 2, p. 185-194, 2009.

MUELLER-DOMBOIS; D.; ELLENBERG, $\mathrm{H}$. Aims and methods of vegetation ecology. New York: Wiley, 1974. 547 p.

NASCIMENTO, A. R. T. et al. Estrutura e classificação de um remanescente de floresta ripária no município de Lages, SC. Ciência Florestal, Santa Maria, v. 21, n. 2, p. 209-218, 2011.

NEGRINI, M. et al. Dispersão, distribuição espacial e estratificação vertical da comunidade arbórea em um fragmento florestal no Planalto Catarinense. Revista Árvore, Viçosa, $\mathrm{MG}$, v. 36, n. 5, p. 919-930, 2012.

NEGRINI, M. et al. Heterogeneidade florísticoestrutural do componente arbóreo em um sistema de fragmentos florestais no Planalto Sul catarinense.

Revista Árvore, Viçosa, $\mathrm{MG}$, v. 38, n. 5, p. 779-786, 2014.

OKSANEN, J. et al. Vegan: community ecology package. 2014. Disponível em: <http://cran.rproject.org/package $=$ vegan $>$. Acesso em: 30 maio 2014.

OLIVEIRA FILHO, A. T. et al. Differentiation of streamside and upland vegetation in an area of montane semideciduous Forest in southeastern Brazil. Flora, Amsterdam, v. 189, n. 4, p. 287-305,
1994.

R DEVELOPMENT CORE TEAM. R: A language and environment for statistical computing. [ $\mathrm{s}$. 1.]: R Foundation for Statistical Computing, 2014. Disponível em: $<$ http://www.r-project.org $>$. Acesso em: 30 maio 2014.

SCIPIONI, M. C. et al. Distribuição do compartimento arbóreo em gradiente de relevo e solos na encosta Meridional da Serra Geral, RS. Ciência Rural, Santa Maria, v. 40, n. 6, p. 1295-1301, 2010.

SILVA, A. C. et al. Comparação florística de florestas inundáveis das regiões Sudeste e Sul do Brasil. Revista Brasileira de Botânica, São Paulo, v. 30, n. 2, p. 257-269, 2007.

SILVA, A. C. et al. Relações florísticas e fitossociologia de uma Floresta Ombrófila Mista Montana Secundária em Lages, Santa Catarina. Ciência Florestal, Santa Maria, v. 22, n. 1, p. 193-206, 2012a.

SILVA, A. C. et al. Florestas inundáveis: ecologia, florística e adaptações das espécies. Lavras: Editora da UFLA; 2012b.

TOMÉ JÚNIOR, J. B. Manual para interpretação de análise de solo. Guaíba: Agropecuária, 1997. $274 \mathrm{p}$.

VAN DEN BERG, E.; OLIVEIRA-FILHO, A. T. Spatial partitioning among tree species within an area of tropical montane gallery forest in southeastern Brazil. Flora, Amsterdam, v. 194, n. 3, p. 249-266, 1999. 